\title{
Adventures in Drug-like Chemistry Space: From Oxetanes to Spiroazetidines and Beyond!
}

\begin{abstract}
Mark Rogers-Evans ${ }^{\S \star a}$, Henner Knust ${ }^{a}$, Jean-Marc Plancher ${ }^{\mathrm{a}}$, Erick M. Carreira ${ }^{\mathrm{b}}$, George Wuitschik ${ }^{\mathrm{b}}$,
\end{abstract} Johannes Burkhard ${ }^{b}$, Dong B. Li ${ }^{b}$, and Carine Guérot ${ }^{b}$

\$KGF-SCS Industrial Investigator Award 2013

In Honour of Professor Klaus Müller on his $70^{\text {th }}$ Birthday

\begin{abstract}
Recently we have documented research efforts aimed at new classes of oxetanes as well as spiroheteroalicyclic ring systems (which we have termed 'Compact Modules') designed to expand the palette of tailored module scaffolds available to medicinal chemists, which constitute an important role for synthetic chemistry in the drug discovery process. An essential component for this process is to provide access to specific molecular topologies with functional group diversity, essential for generating leads that discriminate among biological targets, therefore promoting selectivity and enhancing the safety profile of the final clinical candidates.
\end{abstract}

Keywords: Chemistry and biology space · Compact modules · Oxetanes · Shape diversity · Spiroazetidines

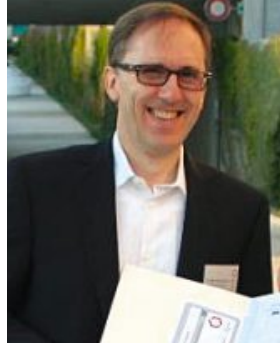

Mark RogersEvans joined F. H off m a n n - L a Roche in Basel in 1996 after completing his $\mathrm{PhD}$ and first post-doc in England (Loughborough \& London, UK) and 2nd post-doc (Waterloo, Canada). After 5 years in process research (process patent Ceftobiprole) he joined Medicinal Chemistry making key contributions to 3 centrally acting clinical candidates and awarded the SCS prize for Best Oral Presentation in 2005 as well as the Roche Plenary lecture at IASOC in 2012 and holds $>80$ publications $\&$ patents.

\section{Introduction: Novel, Drug-like Chemistry Space}

A question we have repeatedly asked ourselves at Roche \& ETH (and also undoubtedly by other chemists) is why the humble, phenyl ring has been so over-represented as a central scaffold in drug structures, rather than e.g. cyclobutanes, ${ }^{[1]}$ which would inherently give a more three-dimensionally vectorized topology, surely more relevant (and selective) to the architecture of protein receptors in the body (Fig. 1). Of course, there were many good reasons why these flat structures have dominated central scaffold construction within the drug discovery world and, after all, almost all the most common, over-the-counter medicines, do contain one, or more phenyl rings at their core or periphery.

However, we began to suspect an analogous case to what has been coined recently as the 'Power Law' ${ }^{[2]}$ prolifically in action leading to an almost unconscious

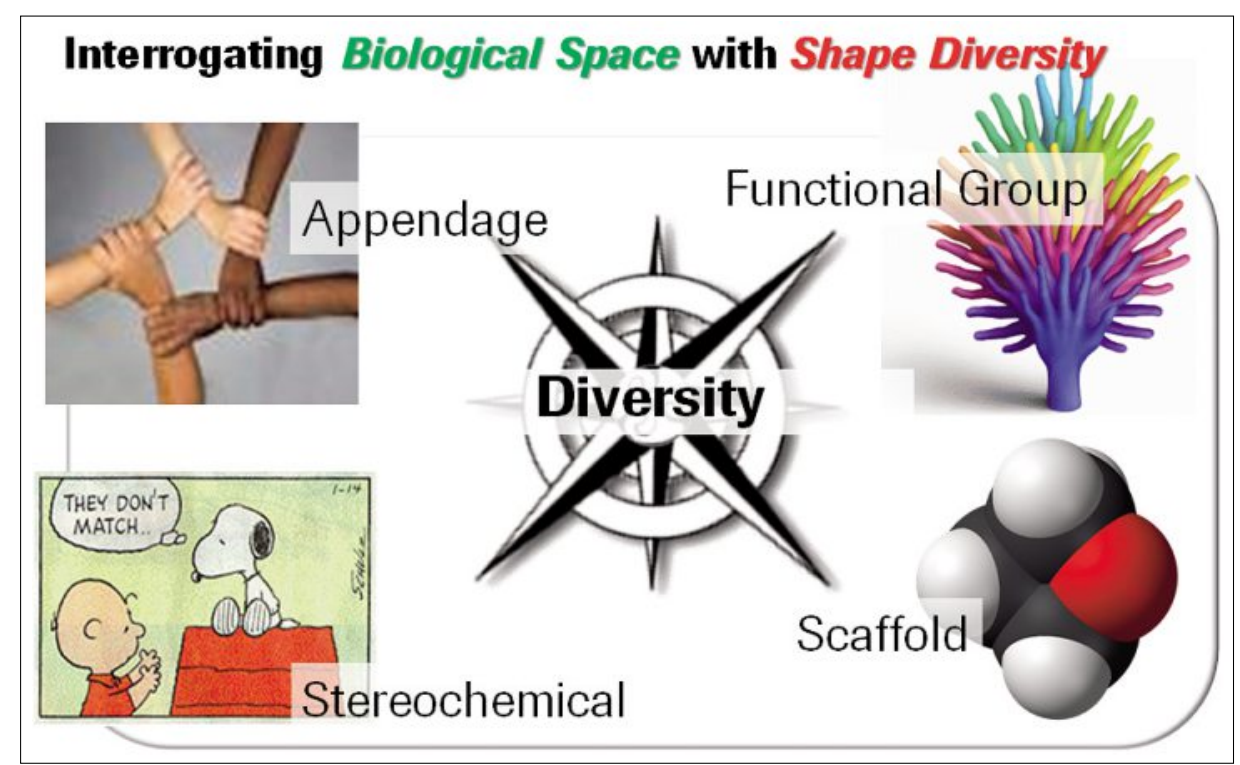

${ }^{\star}$ Correspondence: Dr. M. Rogers-Evans Tel.: +41616882245

E-mail: mark.rogers-evans@roche.com

aF. Hoffmann-La Roche AG

Pharma Research and Early Development Discovery Chemistry

Roche Innovation Center Basel

Grenzacherstrasse

$\mathrm{CH}-4070$ Basel

bLaboratorium für Organische Chemie der ETH

Vladimir Prelog Weg 3

$\mathrm{CH}-8093$ Zürich

Fig. 1. The importance of shape diversity in molecules directed at biological targets. ${ }^{[2]}$ 
auto-selection by scientists who were very comfortable with this ubiquitous motif, or close derivatives thereof such as pyridine/ pyridazine etc. Nevertheless, it was also clear that the nature of the phenyl ring and its lipophilic character, unspecific binding characteristics, low ligand efficiency, forced flat topology and limited solubility might, or even should, exclude it from many drug cores. ${ }^{[3]}$ The advantage, of course, is that scientists know very well how to easily derivatize such scaffolds with a range of aromatic directed or non-directed addition, substitution, cross-coupling and even insertion reactions and, of course, feel comfortable to start their creative sketches on paper with some variation of a substituted phenyl core. In 2005, Prof. Klaus Müller at Roche Basel used his unique view of chemistry whilst also sketching, and focused upon contemplating structures that would address the fundamental property characteristics of drug-like molecules to modulate positively their physico-chemical, metabolic and safety-like properties. ${ }^{[4]}$ Thus we set up a doctoral program in collaboration with Prof. Carreira at ETH, Zurich, engaging Georg Wuitschik to examine the neglected oxetane ring as a possible surrogate of the gem dimethyl and -carbonyl motif grafting it to a prototypical drug-like structure and examining its properties. Soon after, we became fascinated with spirocyclic oxetane structures as surrogates of $e . g$. isomeric piperidones which in turn led to spiroazetidine (Johannes Burkhard), 'angular' spiroazetidines (Henner Knust/ Carine Guérot) as piperazine and amino piperidine surrogates and eventually general vectorized spirocyclic structures (Dong Bo Li) which we imagined could be functionalized to selectively navigate between central and peripheral locations of the body. Subsequent outsourced up-scaling and utilization within Roche projects (Jean-Marc Plancher) amply demonstrated the potential of these modules to expand the current drug space as well as chemists' conscious building block selection. ${ }^{[5]}$ This article serves, therefore, to describe some aspects of the Roche-ETH playground in 'compact modules' and their uptake in selected pharmaceutical programs (Fig. 2).

\section{The Journey Starts: Oxetanes}

\section{History, General Properties/ Reactivity}

Oxetanes, although known since $1878,{ }^{[6]}$ have long lived in the shadows of their three-, five- and six-membered cyclic-ether brethren. Epoxides find broad use because of their reactivity, while tetrahydrofurans and -pyrans are widely found targets of synthesis themselves. Neither seemed to be true for oxetanes: those in-

\section{Evolution of Roche-ETH Collaboration}

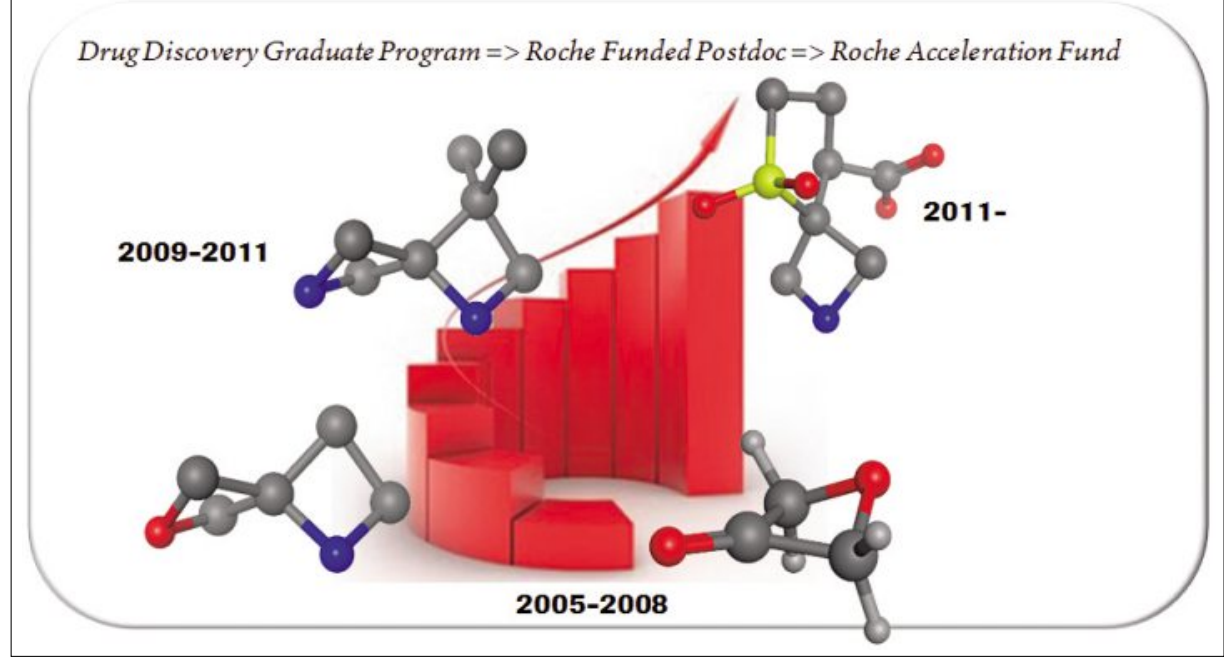

Fig. 2. Expanding the synthesis and utility of four-membered $\mathrm{O}$ and $\mathrm{N}$ systems during the RocheETH collaboration.

terested in structural properties often perceived oxetanes to be too reactive or unstable to be useful targets, whilst curiously those looking for chemical reactivity found that often harsh conditions were required to open oxetanes. Literature suggests that despite the ring strain of oxetanes being roughly the same as epoxides, ${ }^{[7]}$ nucleophilic opening of oxetanes is ceteris paribus much slower compared to epoxides. ${ }^{[8]}$ It is especially the case that substitution at the 3-position shields the 2-position from $\mathrm{SN}_{2}$-type attack, while lack of substitution at the 2-position disfavors formation of carbocations, intermediates in $\mathrm{SN}_{1}$-type ring mechanisms. Therefore, we speculated that 3-substituted oxetanes might occupy a sweet spot in terms of chemical stability and expected physicochemical properties that would warrant efforts to improve on the synthetic access routes towards them.

\section{Analogy to gem-Dimethyl and -Carbonyl Compounds}

Introduction of steric bulk has found wide use in medicinal chemistry to fill receptor pockets and deflect metabolic attack away from sectors of the molecule. Yet, commonly used motifs, such as gem-dime- thyl groups, lead to increased lipophilicity which is often undesirable. Oxetanes mimic in many ways the shape of a gem-dimethyl group, but are intrinsically much less lipophilic due to the hydrophilic embedded oxygen. As shown in Fig. 3, oxetanes also exhibit considerable similarity to carbonyl compounds without their concomitant chemical reactivity. ${ }^{[9]}$

\section{Building Block Strategy for Synthetic Access}

A search of the literature at the outset of the project revealed a paucity of methods to prepare 3-substituted oxetanes. [10] Thus, whatever beneficial properties oxetanes may impart to a scaffold of interest, their practical use will be limited unless short synthetic routes for their preparation exist. Variations of the Williamson ether synthesis most often used to prepare 3-substituted oxetanes were deemed unsuitable for application to advanced scaffolds because of low yield and functional group intolerance. Therefore, preparation of a small set of oxetane-containing building blocks was pursued with the aim of enabling expeditious access to a broad variety of relevant oxetanes.

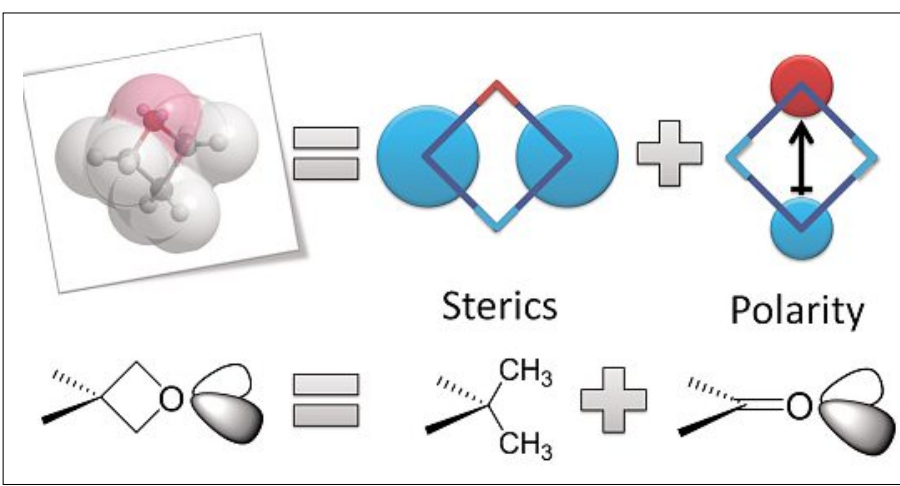

Fig. 3. Oxetanes described as a combination of steric bulk and polarity or a chimera of a carbonyl and a gem-dimethyl group. 


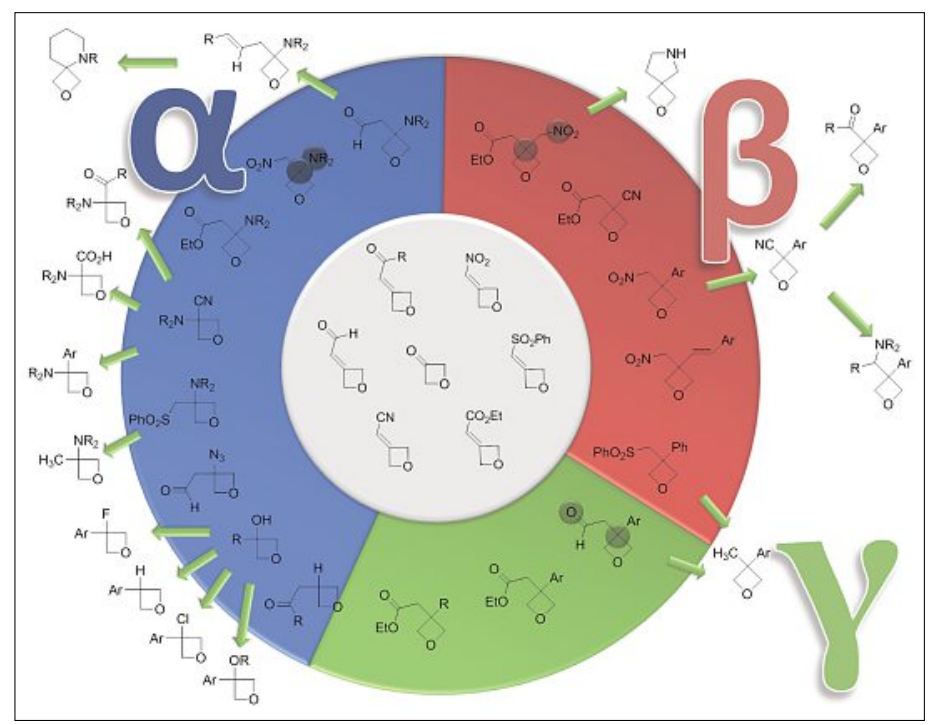

Fig. 4. Oxetan-3-one as a central building block for the preparation of a wide variety of 3-substituted oxetanes.

An overview of some of the building blocks that were developed starting from oxetan-3-one, a compound that is now available commercially on multi-kg scale is shown in Fig 4. ${ }^{[11]}$

A focused program of research revealed that a wide variety of nucleophiles can be added to oxetan-3-one or one of the Michael acceptors derived from it. Release of strain upon addition to the double bond is believed to more than compensate for the steric hindrance around the double bond, thus leading to unusually facile conjugate additions with a broad variety of nucleophiles. ${ }^{[12]}$

\section{Property Comparison and Chemical Stability}

Although there are no universal rules, there are some general guidelines that govern how introduction of an oxetane will change the physicochemical properties of a given molecule. Three main factors seem to drive the changes observed: high dipole moment of the oxetane and its ability to form hydrogen bonds reduce lipophilicity and often the liability for metabolic attack. The ethereal oxygen via its inductive effect withdraws electron density from proximal amines, thus reducing their basicity. Steric bulk of the oxetane ring will often have a pronounced effect on conformational preference in open-chain as well as in spirocyclic settings. ${ }^{[12,13]}$ The magnitude of these changes depends upon the structural context, yet increases in aqueous solubility by a factor of more than 4,000 have been observed when replacing a gem-dimethyl group with an oxetane.[14]

\section{Spirooxetanes - Analogy to Morpholine}

Spirocyclic oxetanes of the type shown in Fig. 5 display a striking shape similarity to morpholine, a widely found motif in marketed drugs. Frequently introduced to increase aqueous solubility of the underly- ing scaffold, morpholines are often subject to metabolic attack and cleavage. We hypothesized that spirocyclic oxetanes subtanes designed to mimic morpholine. stituting morpholine would not only prove metabolically more resistant and more hydrophilic, but by merit of their diverse shape would serve as interesting building blocks in their own right.

By preparing the scaffolds shown in Fig. 5B and comparing their properties with the corresponding morpholine, we could show that they are chemically stable and cover a wide spectrum of physicochemical properties. ${ }^{[9]}$ Several of the underlying secondary amines as well as a large variety of oxetane building blocks have now become commercially available for facile grafting on scaffolds of interest. Similar trends have been observed for the corresponding 1,4-piperazine analogue.

\section{Uptake into General Medicinal Chemistry Projects}

The numbers of 3-substituted oxetanes newly synthesized within Roche as well as new patents over time combined with the

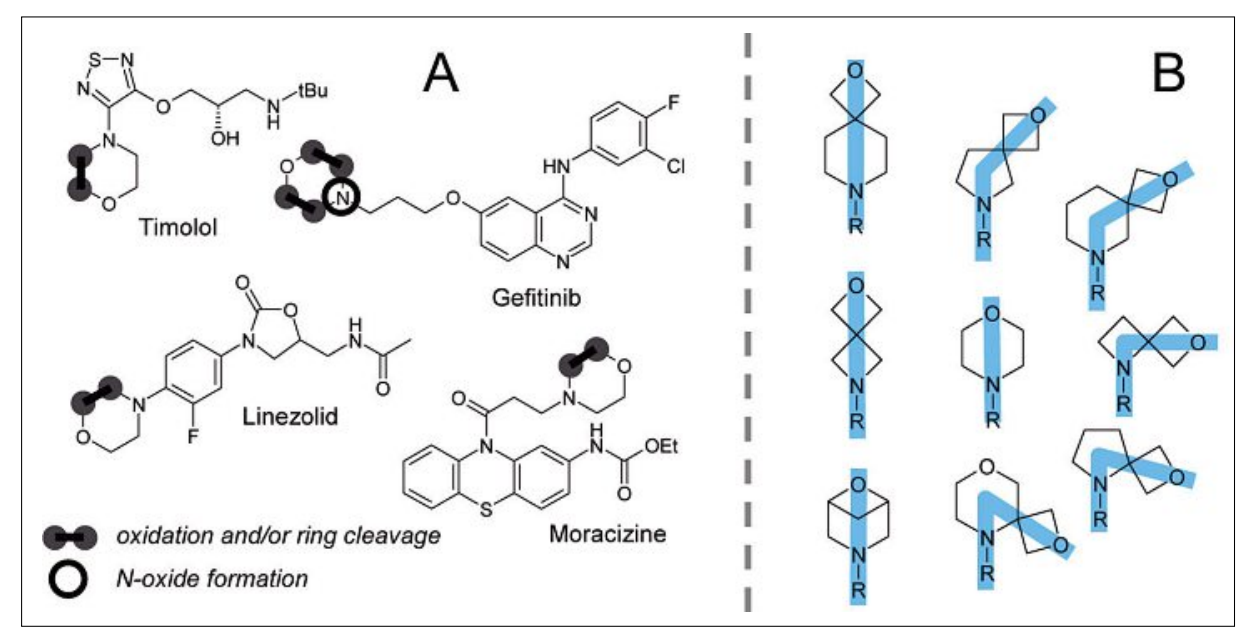

Fig. 5. A) Marketed drugs displaying a metabolically labile morpholine unit. B) Spirocyclic oxe-

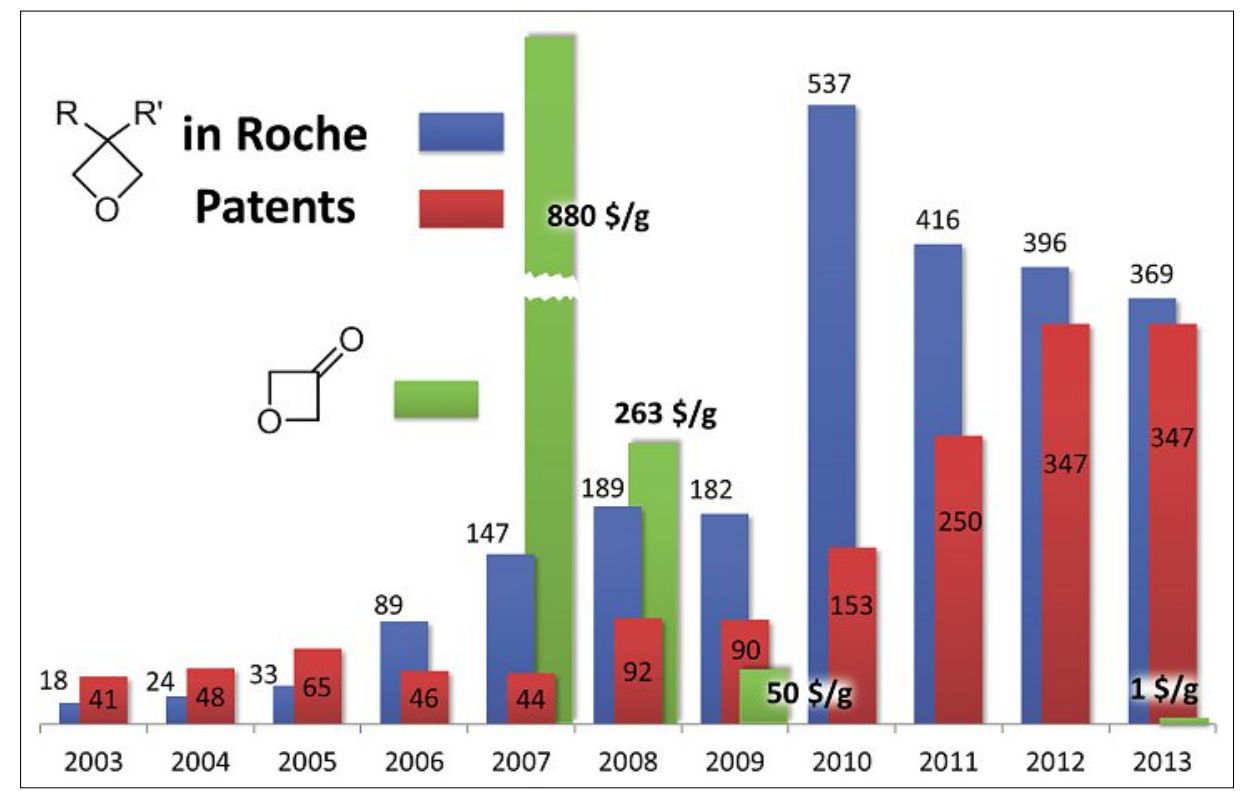

Fig. 6. Rise of interest in oxetanes reflected in their occurrence in the patent literature as well as Roche-internal databases, and the decline of the price of oxetan-3-one. ${ }^{[16]}$ 
price of oxetan-3-one are shown in Fig. 6. We use these figures as surrogate markers for the success of the 'oxetane concept'. In the number of compounds they reflect the increase in measurable commitment of resources as well as, in the price of oxetane-3-one, its commoditization as a reaction for increased demand. Symbolic of the development potential of oxetanes may be the discovery of Crenolanib (Fig. 7), an oxetane-containing tyrosine kinase inhibitor, currently being investigated in several phase II clinical studies. ${ }^{[15]}$

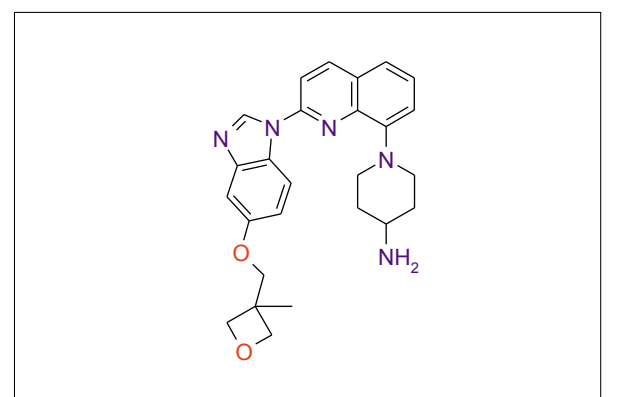

Fig. 7. Structure of Crenolanib.

This trend can also be seen in publications which greatly expanded on our initial work and provided new avenues for accessing a large variety of oxetanes. ${ }^{[17]}$

\section{Oxetane Analogues of Commercial Drugs: Thalidomide and Lenalidomide}

As described above, oxetanes are often used in drug discovery to enable physicochemical and metabolic property enhancement for the structures to which they are grafted. A fine example is the replacement of a carbonyl group by a 3,3-disubstituted oxetane, which distinctively alters chemical and metabolic pathways, but keeps a polar oxygen atom in similar proximity to the framework of the scaffold. Thalidomide (Fig. 8) was introduced in the late 1950s and early 1960 s as an antiemetic and sedative with a devastating effect, causing more than 10 '000 children to be born with numerous severe birth defects. ${ }^{[18]}$ Studies have led to the conclusion that the $(+)-R$ isomer acts as a sedative and the (-)- $S$ form as a teratogen and that the two forms interconvert in the blood plasma due to the acidity of the $\alpha$-proton of the carbonyl group of the imide moiety. A revival of thalidomide in drug discovery started in 1994 when the compound was used for treating leprosy and was found to prevent the growth of blood vessels in solid tumors, therefore acting as an anti-cancer agent. ${ }^{[19]}$ Further evidence has indicated that an unknown thalidomide metabolite might be the active agent. In order to test this hypothesis and eradicate the potential for in vivo racemization we designed an oxetane analog of thalidomide, complemented with a similar analog of lenalidomide, an approved drug for the treatment of multiple myeloma.

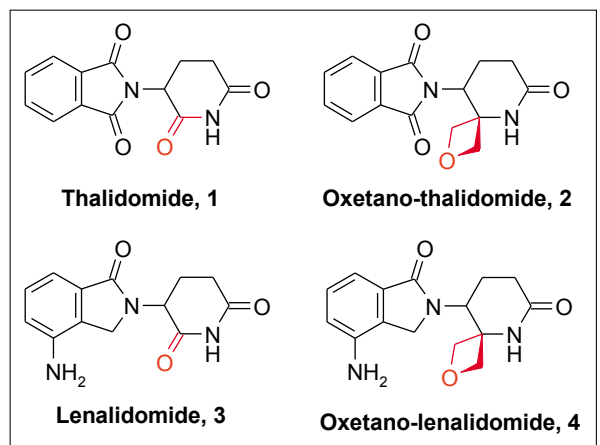

Fig. 8. Thalidomide, lenalidomide and corresponding oxetane analogs.

The target compounds were prepared efficiently in 7-8 steps from methyl $\gamma$-nitrobutanoate 5 and oxetan-3-one 6 (Fig. 9). [20] The starting materials were allowed to react in a Henry addition-condensation and 4-methoxybenzylamine was then added in a conjugate fashion to the formed Michael acceptor 7. The nitro group was first subjected to reduction to the corresponding oxime 8, and then lactam 9 formed under reflux in xylenes. Finally, Raney-Ni/H duction of the oxime yielded crucial amine 10, which was converted to both rac-oxetano-thalidomide and -lenalidomide in few simple steps. Amines $\mathbf{1 0}$ could also be resolved, which were subsequently taken forward to the final compounds, yielding both oxetane analogs in racemic and enantiomerically pure forms.

When comparing the oxetane analogs with thalidomide and lenalidomide, a decrease in lipophilicity, an increase of $\mathrm{p} K$, an increase in solubility, and reduced membrane permeability was observed (Fig. 9b) Importantly, metabolic clearance of oxetane compounds was less pronounced and also plasma stability was greatly increased. While thalidomide can be classified as 'unstable' in a human plasma stability assay (after $5 \mathrm{~h}$ incubation only $40 \%$ of the initial concentration was present), its oxetane analog is 'stable' (74\%). The differences for lenalidomide are less pronounced but point in the same direction. These experiments underscore unexpected benefits of oxetanes in drug discovery that surface in this case for plasma stability. While in vitro data is available, additional in vivo stability data will be needed in combination with assaying the teratogenic potential of these oxetane analogs.

\section{A Selection of Recent Oxetane Module Applications in Roche Medicinal Chemistry}

Straight from their roots, oxetane, spiro-oxetanes and other 'Compact Modules' were designed to address three of the common challenges faced by medicinal chemists ie. i) identification of a proprietary space by introducing novel chemical entities; ii) incorporating polar residues to improve physicochemical properties and

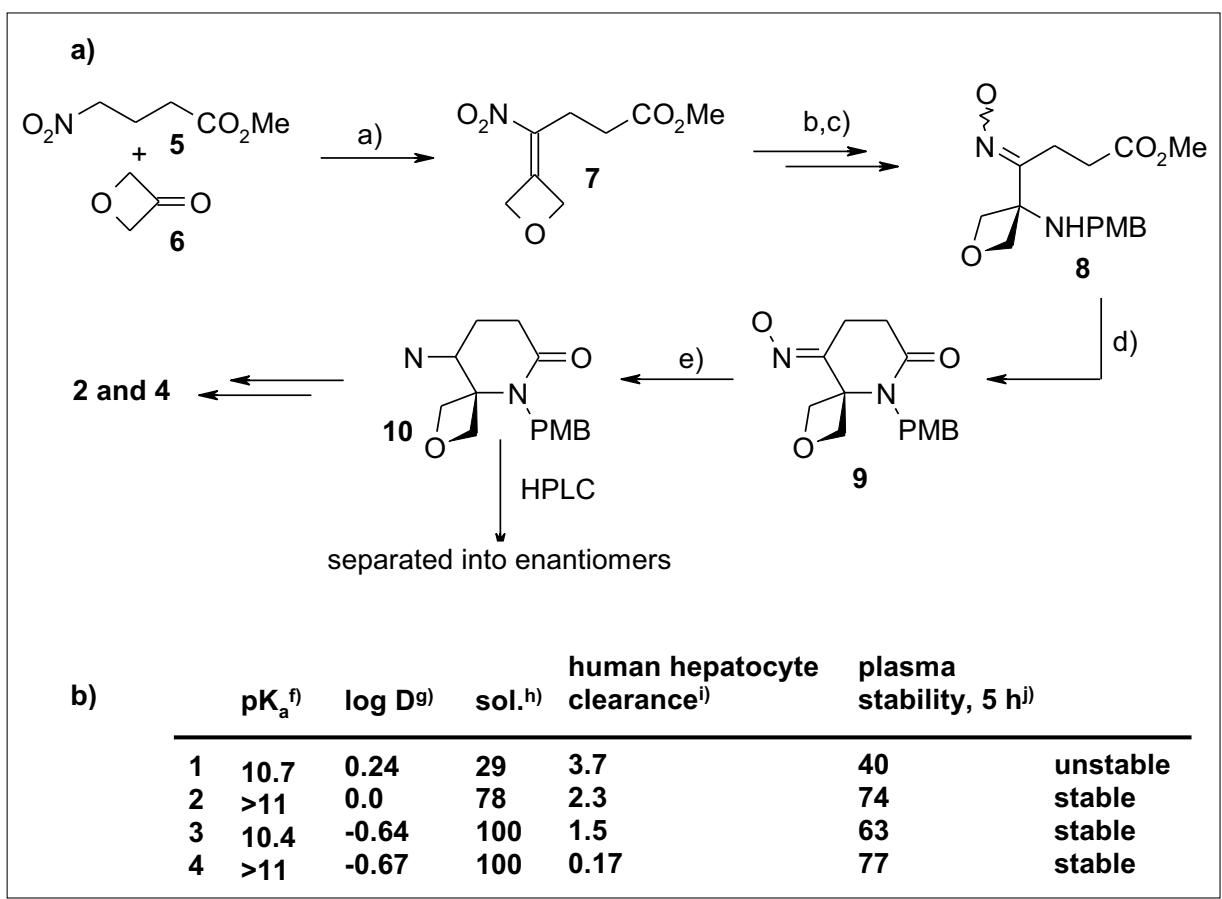

Fig. 9. a) Synthesis of oxetane compounds. Reagents and conditions: a) i. $\mathrm{Et}_{3} \mathrm{~N}$, ii. $\mathrm{MsCl}, \mathrm{Et}_{3} \mathrm{~N}$; b) p-MeO- $\mathrm{C}_{6} \mathrm{H}_{4} \mathrm{CH}_{2} \mathrm{NH}_{2}$; c) $\mathrm{BnBr}, \mathrm{KOH}, \mathrm{Bu}_{4} \mathrm{Nl}$; d) xylenes, $140{ }^{\circ} \mathrm{C}$; e) $\mathrm{H}_{2}$, Raney-Ni; $50 \%$ yield from 5. b) Physicochemical and biological properties: f) ionization constants at $23^{\circ} \mathrm{C}$ in water; g) logarithmic $n$-octanol/water distribution coefficient at $\mathrm{pH} 7.4$; h) intrinsic solubility $[\mu \mathrm{g} / \mathrm{ml}]$ at $\mathrm{pH} 6.5$; i) intrinsic clearance rates $\left[\mu \mathrm{l} / \mathrm{min} / 10^{6}\right.$ cells]; j) stability in human plasma after 5 hours incubation time, expressed as a percentage of the initial concentration. 
metabolic stability; iii) to explore conformations unattainable with other more common scaffolds. $\left.{ }^{[9 a}, 10,12,14,21,22\right]$ Some of these applications in recent Roche Medicinal Chemistry projects are exemplified below:

\section{BTK: 2-Oxa-6-azaspiro[3.3]heptane as Bioisoster of Morpholine with an Improved Profile}

Bruton's tyrosine kinase (BTK) is implicated in immunodeficiency disease. Although its exact mechanism of action remains unknown, it plays a crucial role in B-cell maturation as well as mast cell activation. In the course of this program, morpholinoamides were identified as promising BTK inhibitors, ${ }^{[23]}$ however, clearance in microsomal preparation was on the high side (compound 11, Fig. 10). The metabolism pathway involved mainly oxidation on the morphine 2-position, leading eventually to ring opening and further oxidation processes. Bioisosteric replacement of the morpholine by 2-oxa-6-azaspiro[3.3]heptane significantly improved the metabolic stability of compound 12, while improving aqueous solubility. Affinity for the target was marginally affected.

\section{Oxetane Conformational Preference and pKa: The RSV Case}

Human respiratory syncytial virus (RSV) causes respiratory tract infections. It is a major cause of lower respiratory tract infections and hospital visits during infancy and childhood. Derived from a virtual screening based on the X-ray apo-structure of the virus surface F-protein, compound 13 was potent but metabolic stability was poor. Introduction of a gem-dimethyl could improve the clearance of compound 14, however with a slight reduction in potency. Introduction of an oxetane proved critical to restore the affinity. This was rationalized as a consequence of conformer restriction. Inhibitors docked in the F-protein required a $120^{\circ}$ dihedral angle for optimal fit. According to the Cambridge Structure Database, this condition was perfectly matched by the oxetane derivative $\mathbf{1 5}$ with two symmetric conformers (Fig. 11, diagram 1), but not by the gem-dimethyl 14 which equally favors a $0^{\circ}$ or a $120^{\circ}$ dihedral angle (Fig. 11, diagram 2). ${ }^{[12,24]}$

Additionally, in compound 5, the oxetane lowered $\mathrm{pKa}$ of the terminal amine by ca. $2 \log$ units, a reduction probably at the origin of a more favorable volume of distribution. ${ }^{[25]}$

\section{Oxetane for Improved Metabolic Stability: ALK Inhibitors}

Anaplastic lymphoma kinase (ALK) receptor tyrosine kinase is considered as an attractive therapeutic target for human cancers, especially non-small cell lung cancer (NSCLC). Derived from an HTS hit, the

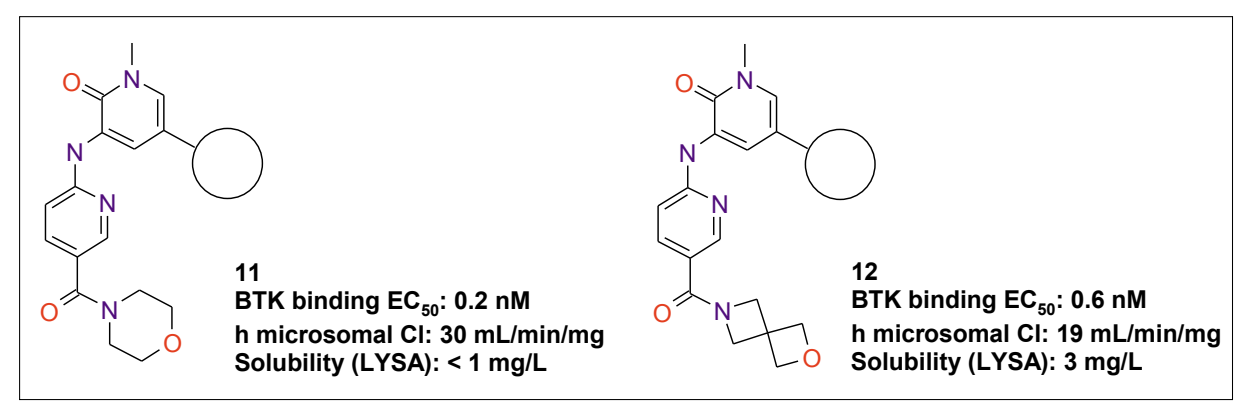

Fig. 10. 2-oxa-6-azaspiro[3.3]heptane as a bioisosteric replacement of morpholine in the BTK program.

6,6-dimethyl-11-oxo-6,11-dihydro-5Hbenzo[b]carbazole series proved to be ATP competitive (Fig. 12). Isopropylpiperazine 16 was potent against ALK, however metabolic clearance, particularly in human microsomal preparation, was high. $\mathrm{N}$-oxetanyl derivatives $\mathbf{1 7}$ and $\mathbf{1 8}$ demonstrated lower $\mathrm{Cl}$ values, at the expense of the target affinity. High affinity could be restored by the replacement of the piperazine by a piperidine, while the metabolic stability was maintained in a favorable range. [26]

\section{Oxetane to Improve Solubility and Microsome Metabolic Stability: CB2 \\ The cannabinoid receptor type 2 (CB2)} is particularly expressed in the peripheral tissues of the immune system, therefore primary research on the functioning of the $\mathrm{CB}_{2}$ receptor has focused on the receptor's effects on the immunological activity of leukocytes. In the course of the optimization of the advanced compound 19, ${ }^{[27]}$ incorporation of an oxetane in place of the isopropyl led to a drastic reduction of the

lipophilicity (-0.9 log unit, Fig. 13). This in turn improved the aqueous solubility by sixfold and the microsomal stabilities in both human and rat preparations. In aqueous solution, both compounds 19 and 20 presented similar stability: degradation was observed at $\mathrm{pH}=1$, whereas less acidic conditions $(\mathrm{pH}=4,6.5,8$, and 10) did not lead to significant decomposition. ${ }^{[25]}$

\section{Oxetane and Chemical Stability}

The Lewis basicity and ring strain of the oxetane could set the stage for potential, unwanted acid sensitivity. Indeed acid-catalyzed oxetane ring opening is a convenient method to introduce a propanol moiety. ${ }^{[28]}$ Such acid sensitivity in aqueous media was observed in the course of the $\mathrm{H}_{3} \mathrm{R}$ inverse agonist project and led to the de-selection of the oxetane derivative $\mathbf{2 1}$ (Fig. 14a).[27] However, such acidic- and, more generally chemical sensitivity is highly dependent on structural surrounding and should be considered on a caseby-case basis.

In an undisclosed advanced project, the

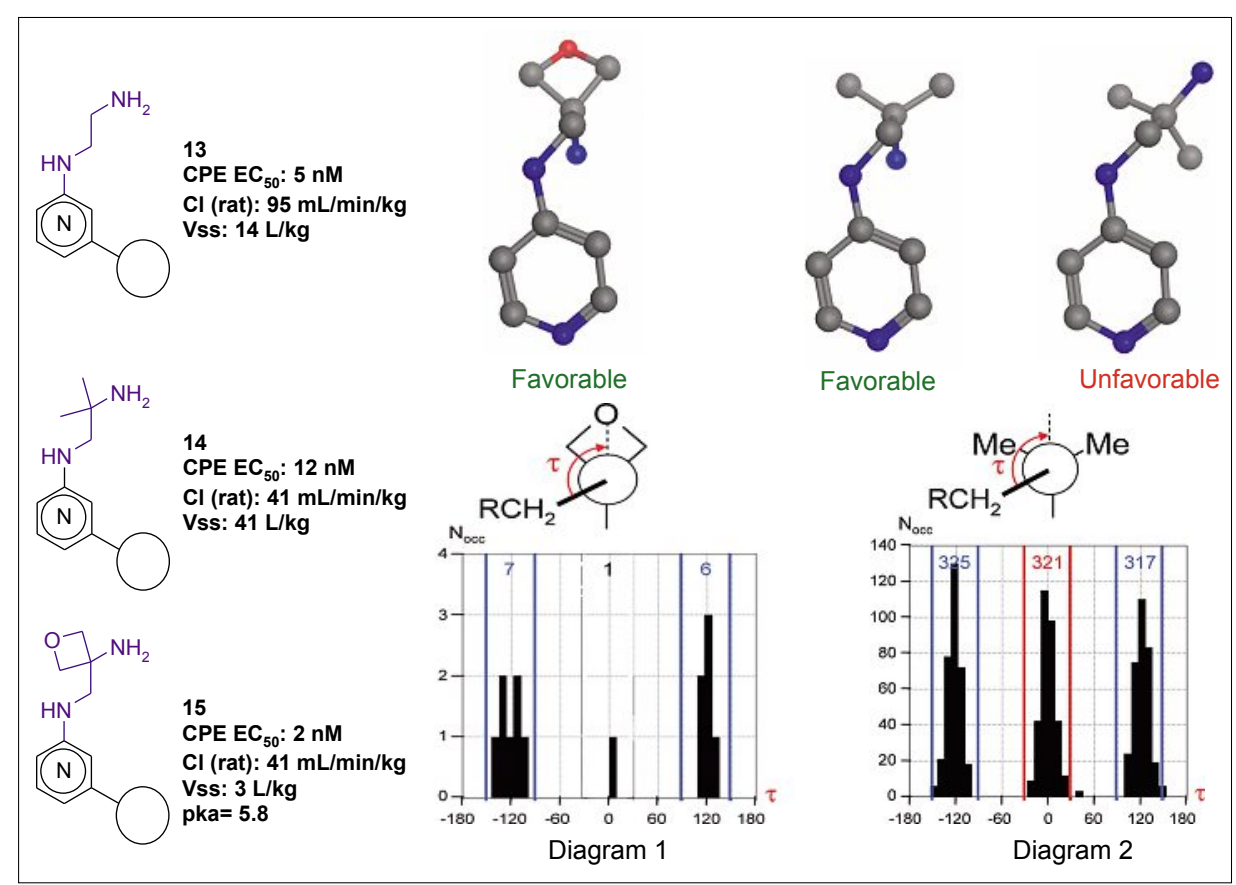

Fig. 11. Conformational preference of amino-oxetane and effect on potency and volume of distribution in the RSV program. 


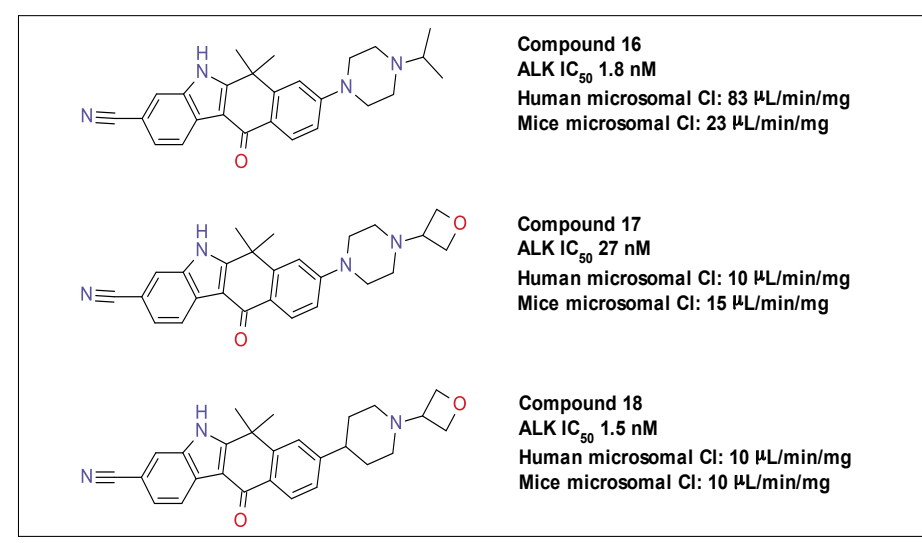

Fig. 12. Influence of oxetane on affinity and metabolic stability.

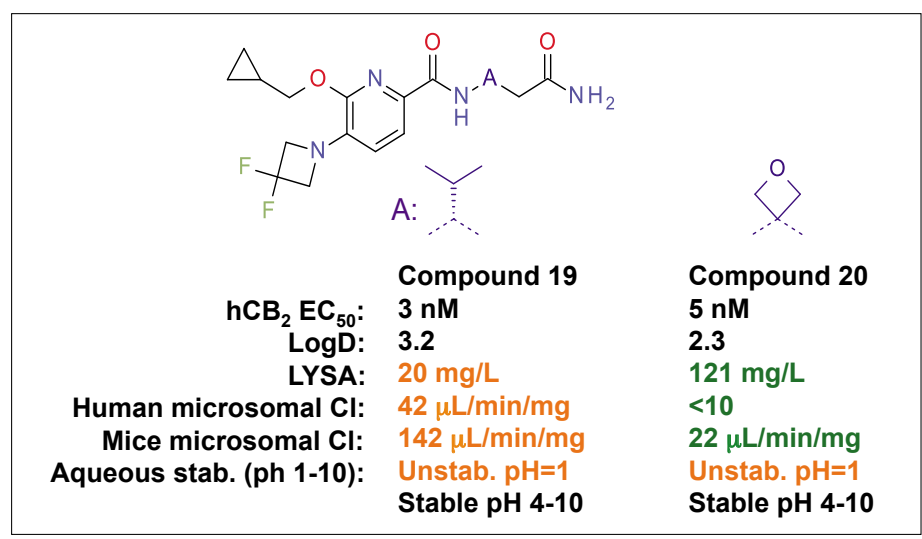

Fig. 13. Solubility and microsomal clearance improvements in CB2 project. oxetane ring survived very vigorous conditions, including strong Lewis and Brønsted acids (Fig. 14b). Although some of the yields were modest, the oxetane stability was remarkable in this case.

\section{The Journey Continues Towards Further 'Compact Modules': Spiroazetidines}

A natural extension of the spirooxetane system led us to examine the corresponding series of spirocyclic, angular spirocyclic and fused azetidine modules ${ }^{[22]}$ as e.g. bioisosteric replacements (Fig. 15) of the central piperid-4-yl ether scaffold; exemplified here for a class of inhibitors of the enzyme soluble epoxide hydrolase ( $\mathrm{sEH})$.

X-ray overlays (Fig. 16) of the minimised conformations of the 4-substituted piperidine $I$ and the spirocyclic angular or linear bis-azetidines ( $\mathbf{2 4}$ and $\mathbf{2 6}$ ) as well as the fused azetidine (25) revealed the potential of these modules as bioisosteres for $\mathbf{2 3}$ regarding a good match of exit vectors.

\section{Novel Thia/Oxa-Azaspiro[3.4]oc- tanes}

As mentioned, the identification of novel multifunctional modules through design and synthesis constitutes a critical role to provide access to specific molecular topologies with functional group diversity, essential for generating leads that discriminate among biological targets, therefore promoting the selectivity and enhancing the safety profile of the final candidates. We have described the collections of spirocyclic oxetanes $\left.{ }^{[9 a}, 10,12,14,21\right]$ and azaspiro[3.3] heptane ${ }^{[22]}$ as building blocks, which provide entry into novel chemical, pharmacological, and proprietary space. In line with these interests we continued to expand the collection of spirocycles by exploring new structures. In this context, our pursuits have included thia/oxa-azaspiro[3.4]octanes (Fig. 17).

These served to generate uncharted

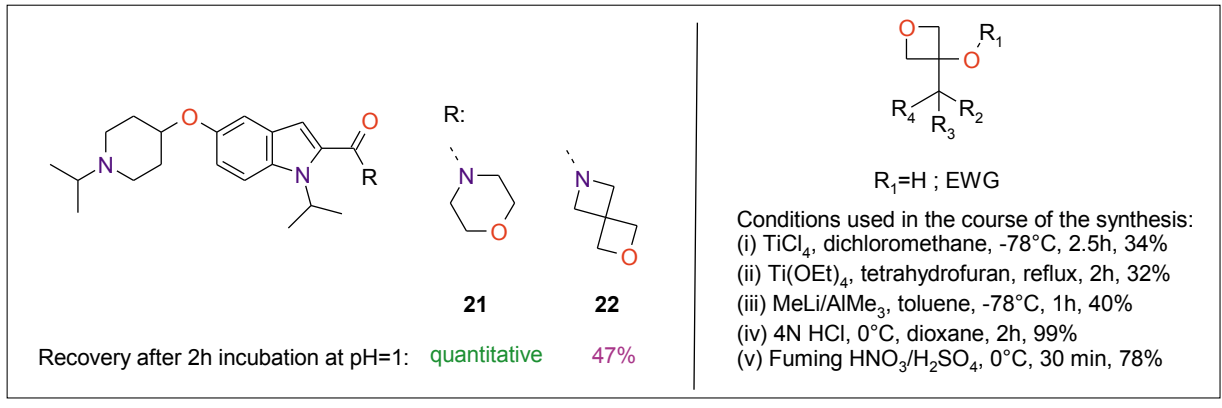

Fig. 14. a) Spiro-oxetane in aqueous media; b) oxetane and chemical stability.

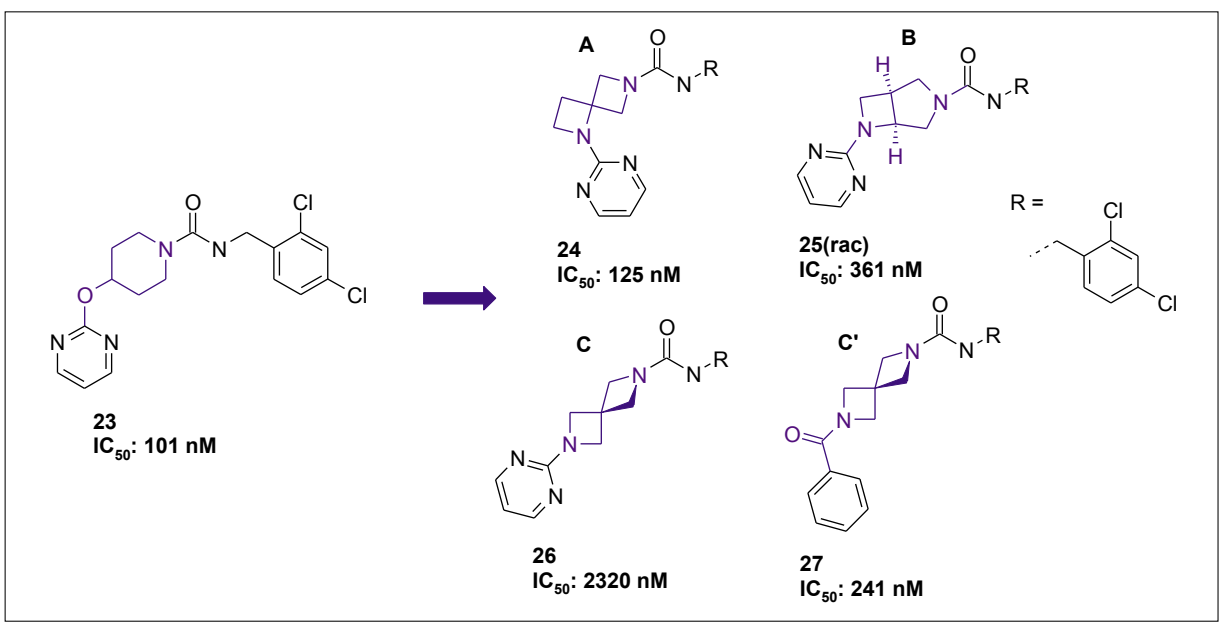

Fig. 15. Spiro and fused bicyclic surrogates.

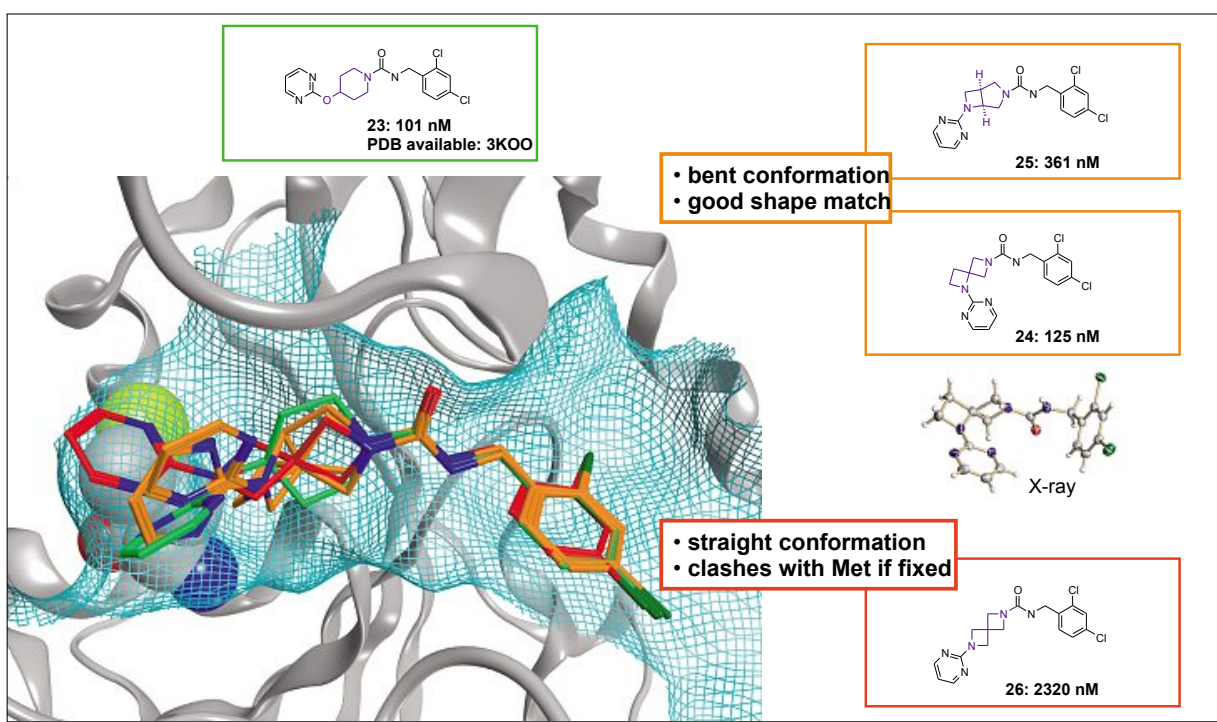

Fig. 16. X-ray overlays of the minimized conformations of 4-substituted piperidine with various bis-azetidines in sEH active site. 
azospiro[3.4]octanes that intuitively resembled 'drug-like' fragments. Through the implementation of robust, scalable and step-economic routes, a total of sixteen designed thia/oxa-azaspiro[3.4]octanes (Fig. 18) have been currently prepared and access to two of these in enantio-enriched form was also established $(90 \% e e)$. $^{[29]}$

We anticipate that the compact nature of these novel modules coupled with inherent tunable physicochemical properties will enable their potential targeting both inside and outside of the brain for drug discovery projects, as well as assure a novel intellectual property position. We anticipate these building blocks will be welcome additions as novel scaffolds to the drug discovery tool box.

\section{Outlook}

More recently, Roche-ETH have begun to examine oxetanyl analogues of some common amino acids, incorporated into short peptides (Fig. 19) in order to examine both stability and secondary structure based elements (to be reported separately).

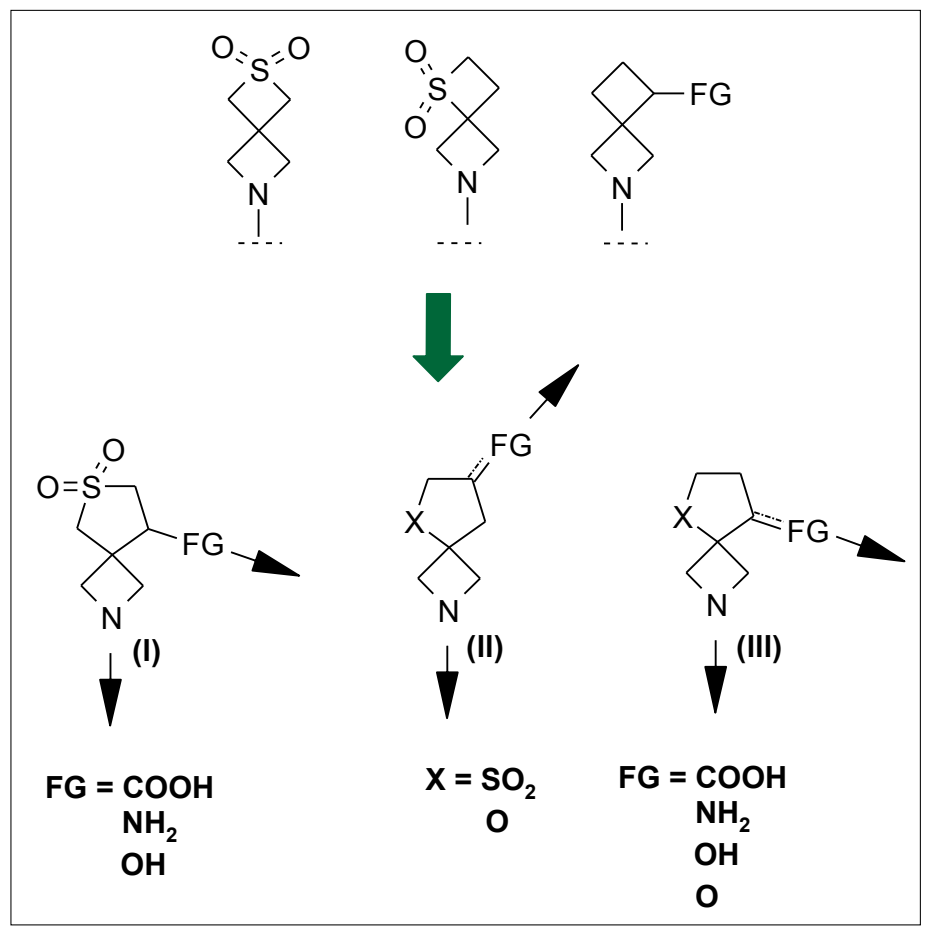

Fig. 17. Evolution of azaspiro[3.4]octanes incorporating sulphones and oxygens shown with variable exit vectors.
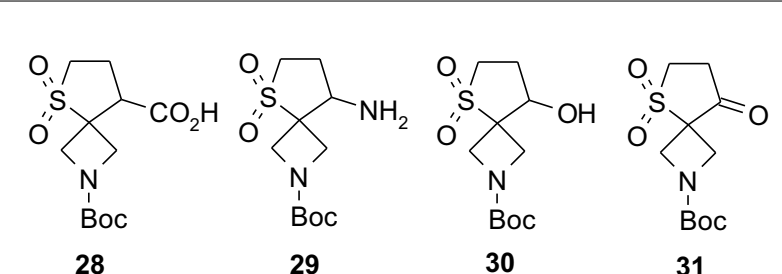<smiles>O=C(O)C1CS(=O)(=O)CC12CN(C(=O)O)C2</smiles><smiles>CC(C)(C)OC(=O)N1CC2(C1)CS(=O)(=O)CC2N</smiles><smiles>O=C(c1ccccc1)N1CC2(C1)CS(=O)(=O)CC2O</smiles><smiles>CC(C)(C)OC(=O)N1CC2(CSCC2=O)C1</smiles>
34 35
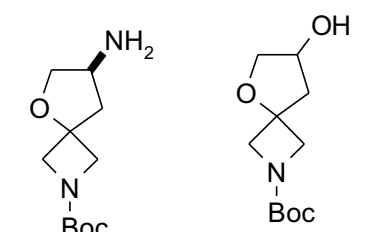

$(-)-39,90 \%$ ee<smiles>NC1CC2(CN(C(=O)OCc3ccccc3)C2)S(=O)(=O)O1</smiles>

36

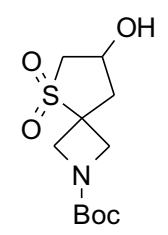

37

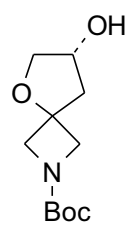

$(-)-40,90 \%$ ee

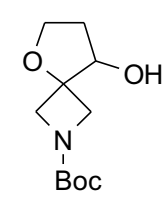

41

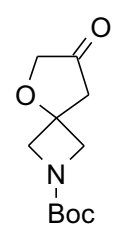

38

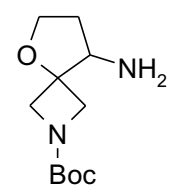

42
In addition, the renaissance of phenotypic screening holds much promise for the (re)positioning of module surrogates of e.g. marketed compounds with enhanced safety, metabolic and pharmacologically selective properties. In this regard, we have been recently attracted to the anti-psychotic field which suffers particularly from polypharmacological modalities (to be reported separately).

In conclusion, our adventures in exploring novel, tractable surrogates of traditional chemistry building blocks has enlarged the medicinal chemists' palate of tools with which to usefully explore the property characteristics of small molecule and peptide modalities. The ideal 'Compact Module' should have tunable polarities affecting the phys-chem and safety parameters of their parent and be amenable to vectorization. The latter provides ready shape diversity, a feature critical to contemporary compound collections looking to access poorly or uncharted three-dimensional macromolecular biological targets. An essential component for this process is to provide access to specific molecular topologies with functional group diversity, essential for generating leads that discriminate among biological targets, therefore promoting the selectivity and enhancing the safety profile of the final candidates.

Received: July 21, 2014

[1] For cyclobutanes, see: a) D. Belluš, B. Ernst, Angew. Chem., Int. Ed. 1988, 27, 797; b) V. M. Dembitsky, J. Nat. Med. 2008, 62, 1.

[2] For structural diversity in organic chemistry, see: a) A. H. Lipkus, Q. Yuan, K. A. Lucas, S. A. Funk, W. F. Bartelt, R. J. Schenck, A. J. Trippe, J. Org. Chem. 2008, 73, 4443; b) G. W. Bemis, M. A. Murcko, J. Med. Chem. 1996, 39, 2887; c) W. R. J. D. Galloway, A. IsidroLlobet, D. R. Spring, Nat. Commun. 2010, 1, 80; d) J.-L. Reymond, L. Ruddigkeit, L. Blum, R. v. Deursen, WIREs Comput. Mol. Sci. 2012, 2, 717; e) A. Schuffenhauer, P. Ertl, S. Roggo, S. Wetzel, M. A. Koch, H. Waldmann, J. Chem. Inf. Model. 2007, 47, 47.

[3] For a discussion of aromatic ring count vs developability, see: a) T. J. Ritchie, S. J. F. Macdonald, Drug Discov. Today 2009, 14 1001; b) T. J. Ritchie, S. J. F. Macdonald, R. J. Young, S. D. Pickett, Drug Discov. Today 2011, 16, 164.

[4] For a discussion of drug-like concepts relevant to medicinal chemistry, see: a) P. D. Leeson, B. Springthorpe, Nat. Rev. Drug Discov. 2007, 6, 881; b) G. M. Keserü, G. M. Makara, Nat. Rev. Drug Discov. 2009, 8, 203; c) J. A. Arnott, S. L. Planey, Expert Opin. Drug Discov. 2012, 7, 863. d) N. A. Meanwell, Chem. Res. Toxicol. 2011, 24, 1420 .

[5] http://pipeline.corante.com/archives/2013/09/10/bring_me_more_cute_ring systems.php

[6] M. Reboul, Ann. Chim. (Paris) 1878, 14, 496.

[7] B. Ringner, S. Sunner, H. Watanabe, Acta Chem. Scand. 1971, 25, 141.

[8] J. G. Pritchard, F. A. Long, J. Am. Chem. Soc. 1958, 80, 4162. For kinetic studies on the mechanism of acid-catalyzed ring opening of oxe-

Fig. 18. Evolution of azaspiro[3.4]octanes incorporating sulphones and oxygens shown with variable exit vectors. 


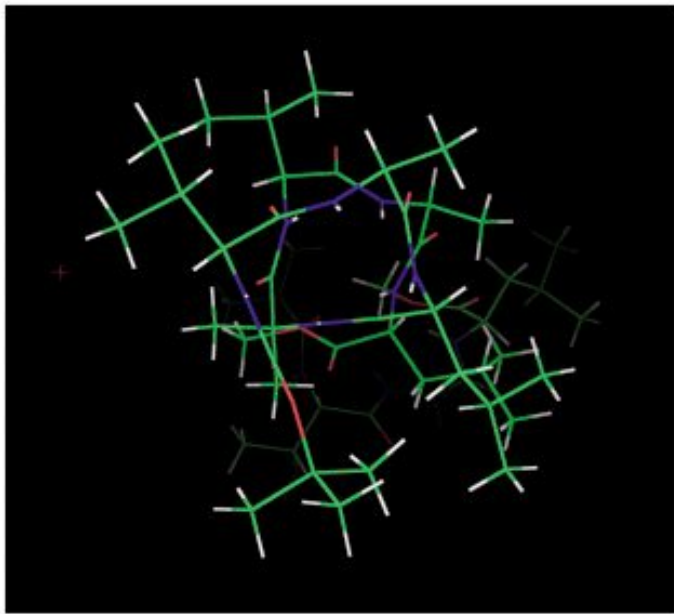

X-Ray of Balaram type peptide 1<smiles>CC(=O)N[C@H](CC(C)C)C(=O)NC(C)C(=O)NC(=O)[C@H](NC(=O)C(C)(C)NC(=O)[C@H](CC(C)C)NC(=O)[C@H](C)NC(=O)[C@H](NC(=O)OCc1ccccc1)C(C)C)C(C)C</smiles><smiles>CC(=O)C(CC(C)C)NC(=O)C(C)NC(=O)C(NC(=O)C1(NC(=O)C(CC(C)C)NC(=O)C(C)NC(=O)C(NC(=O)O)C(C)C)CCOC1)C(C)C</smiles><smiles>CC(=O)OC(CC(C)C)NC(=O)C(C)NC(=O)[C@H](NC(=O)C1(NC(=O)[C@H](CC(C)C)NC(=O)C(C)NC(=O)[C@@H](NC(=O)OCc2ccccc2)C(C)C)CCOC1)C(C)C</smiles>

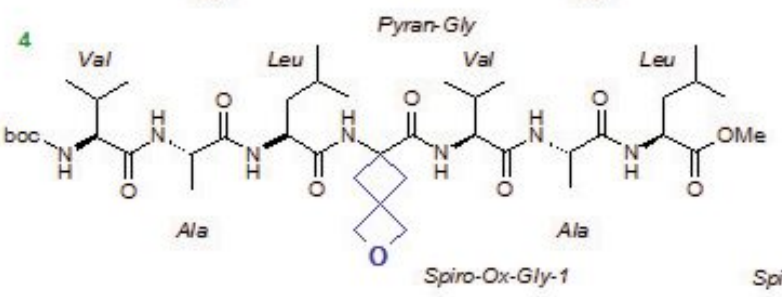

5

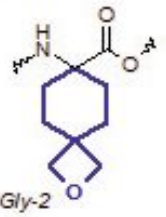

Fig. 19. Module surrogates of a 'Balaram' type peptide. ${ }^{[30,31]}$

tane, see: M. Lajunen, J. -M. Koskinen, Acta Chem. Scand. 1994, 48, 788. For computational approaches to explain the difference, refer to: a) J. L. Wolk, M. Sprecher, H. Basch, S. Hoz, Org. Biomol. Chem. 2004, 2, 1065; b) J. L. Wolk, T. Hoz, H. Basch, S. Hoz, J. Org. Chem. 2001 , 66,915 ; c) A. Sella, H. Basch, S. Hoz, J. Am Chem. Soc. 1996, 118, 416; d) D. Sawicka, K N. Houk, J. Mol. Model. 2000, 6, 158.

[9] G. Wuitschik, M. Rogers-Evans, A. Buckl, M. Bernasconi, M. Märki, T. Godel, H. Fischer, B. Wagner, I. Parrilla, F. Schuler, J. Schneider, A. Alker, W. B. Schweizer, K. Müller, E. M Carreira, Angew. Chem., Int. Ed. 2008, 47, 4512.

[10] G. Wuitschik, E. M. Carreira, M. Rogers-Evans, K. Müller, 'Oxetan-3-one: chemistry and synthesis in Process Chemistry in the Pharmaceutical Industry', Eds.: K. Gadamasetti, T. Braish, CRC Press LLC, Boca Raton, Fla, 2008, p. 217.

[11] Oxetan-3-one costs $72 \mathrm{US} \$ / \mathrm{mol}$ on $3 \mathrm{~kg}$-scale: ACD database, retrieved June 10, 2014

[12] G. Wuitschik, E. M. Carreira, B. Wagner, H. Fischer, I. Parrilla, F. Schuler, M. Rogers-Evans, K. Müller, J. Med. Chem. 2010, 53, 3227.

[13] G. Wuitschik, PhD Thesis ETH Zürich No. 17929, 2008.

[14] G. Wuitschik, M. Rogers-Evans, K. Muller, H. Fischer, B. Wagner, F. Schuler, L. Polonchuk, E M. Carreira, Angew. Chem., Int. Ed. 2006, 45, 7736

[15] a) A. Galanis, H. Ma, T. Rajkhowa, A Ramachandran, D. Small, J. Cortes, M. Levis, Blood 2014, 123, 94; b) for further information, refer to https://clinicaltrials.gov/ct2/ results?term=crenolanib
[16] Number of newly registered oxetanes (Rocheinternal database) and newly published patents containing a 3-substituted oxetane (Reaxys search). Price of oxetan-3-one quoted in USD per gram: cheapest supplier according to ACD database on June 10, 2014.

[17] a) M. A. J. Duncton, M. A. Estiarte, D. Tan, C. Kaub, D. J. R. O’Mahony, R. J. Johnson, M. Cox, W. T. Edwards, M. Wan, J. Kincaid, M. G. Kelly, Org. Lett. 2008, 10, 3259; b) M. A. J. Duncton, M. A. Estiarte, R. J. Johnson, M. Cox, D. J. R. O'Mahony, W. T. Edwards, M. G. Kelly, J. Org. Chem. 2009, 74, 6354; c) P. J. Hamzik, J. D. Brubaker, Org. Lett. 2010, 12, 1116; d) L. Ye, W. He, L. Zhang, Angew. Chem., Int. Ed. 2011, 50, 3236

[18] S. J. Matthews, C. McCoy, Clin. Ther. 2003, 25, 342.

[19] R. J. D'Amato, M. S. Loughnan, E. Flynn, J. Folkman, Proc. Natl. Acad. Sci. U.S.A. 1994, 91, 4082.

[20] J. A. Burkhard, G. Wuitschik, J. -M. Plancher, M. Rogers-Evans, E. M. Carreira, Org. Lett. 2013, 15, 4312 .

[21] For oxetanes and related spirocycles, see: J. A. Burkhard, G. Wuitschik, M. Rogers-Evans, K. Müller, E. M. Carreira, Angew. Chem., Int. Ed. 2010, 49, 9052

[22] For azaspiro[3.3]heptanes, see: a) J. A. Burkhard, C. Guérot, H. Knust, E. M. Carreira, Org. Lett. 2012, 14, 66; b) C. Guérot, B. H. Tchitchanov, H. Knust, E. M. Carreira, Org. Lett. 2011, 13, 780; c) J. A. Burkhard, B. Wagner, H. Fischer, F. Schuler, K. Müller, E. M. Carreira, Angew. Chem., Int. Ed. 2010, 49, 3524; d) J. A. Burkhard, C. Guérot, H. Knust,
M. Rogers-Evans, E. M. Carreira, Org. Lett. 2010, 12, 1944; e) J. Burkhard, E. M. Carreira Org. Lett. 2008, 10, 3525.

[23] N. J. Dewdney, J. Kennedy-Smith, R. K Kondru, B. E. Loc, Y. Lou, J. McIntosh, T. D. Owens, M. Soth, Z. K. Sweeney, J. P. Gergely, US20090306041, 2009.

[24] M. Rogers-Evans, KGF-SCS Lecture, Lausanne, $6^{\text {th }}$ September 2013.

[25] Unpublished data.

[26] a) K. Kinoshita, Y. Ono, T. Emura, K. Asoh, N. Furuich, T. Ito, H. Kawada, S. Tanaka, K. Morikami, T. Tsukaguchi, H. Sakamoto, T. Tsukuda, N. Oikawa, Bioorg. Med. Chem. Lett. 2011, 21, 3788; b) K. Kinoshita, T. Kobayashi, K. Asoh, N. Furuichi, T. Ito, H. Kawada, S. Hara, J. Ohwada, K. Hattori, T. Miyagi, W.-S. Hong, M.-J. Park, K. Takanashi, T. Tsukaguchi, H. Sakamoto, T. Tsukuda, N. Oikawa, J. Med. Chem. 2011, 54, 6286; c) K. Kinoshita, K. Asoh, N. Furuichi, T. Ito, H. Kawada, S. Hara, J. Ohwada, T. Miyagi, T. Kobayashi, K. Takanashi, T. Tsukaguchi, H. Sakamoto, T. Tsukuda, N. Oikawa, Bioorg. Med. Chem. 2012, 20, 1271.

[27] B. Frei, L. Gobbi, M. Rogers-Evans, T. SchulzGasch, U. Grether, M. Nettekoven, S. Roever, A. Kimbara, WO 2014/086705.

[28] R. D. Evans, J. W. Magee, J. H. Schauble, Synthesis 1988, 11, 862 .

[29] For synthesis in detail, see: a) D. B. Li, M Rogers-Evans, E. M. Carreira, Org. Lett. 2011 , 13, 6134; b) D. B. Li, M. Rogers-Evans, E. M. Carreira, Org. Lett. 2013, 15, 4766.

[30] I. L. Karle, J. L. Flippen-Anderson, K. Uma, P. Balaram, Biopolymers 1993, 33, 827.

[31] M. Rogers-Evans, E. M. Carreira, R. Yazaki, T C. Fessard, A. Ross, A. M. Alker, unpublished results. 